\title{
Ivory Exostosis
}

National Cancer Institute

\section{Source}

National Cancer Institute. Ivory Exostosis. NCI Thesaurus. Code C121923.

An osteoma that develops on the surface of the bone. 